\title{
Flood protection structure detection with Lidar: examples on French Mediterranean rivers and coastal areas
}

\author{
Céline Trmal ${ }^{1, a}$, Frédéric Pons ${ }^{1}$ and Patrick Ledoux ${ }^{1}$ \\ ${ }^{1}$ Cerema, Direction Territoriale Méditerranée, Pôle d'Activités des Milles, CS 70499, 13593 Aix en Provence Cedex 3, France
}

\begin{abstract}
This paper aims at presenting different topographic analysis conducted with GIS software in order to detect flood protection structures, natural or artificial, in river floodplains but also in coastal zones. Those computations are relevant because of the availability of high-resolution lidar digital terrain model (DTM). An automatic detection permits to map the footprint of those structures. Then detailed mapping of structure crest is achieved by implementing a least cost path analysis on DTM but also on other terrain aspects such as the curvature. On coastal zones, the analysis is going further by identifying flood protected areas and the level of protection regarding sea level. This article is illustrated by examples on French Mediterranean rivers and coastal areas.
\end{abstract}

\section{Introduction}

Flood protection structures play a major role in a lot of flood events especially for large river and sea flooding. In France, flood structures and infrastructures are managed by a lot of owners. Their locations and/or their past life have sometimes been forgotten. Thus, the knowledge of structures which have a flood protection role is a real stake to prevent floods.

The accuracy of high-resolution digital terrain models (DTM) as Lidar, is an opportunity to analyze systematically large territories and detect flood protection. A Lidar survey was funded by Ministry of Environment, Energy and Sea coordinated by French national geographic institute (IGN) on the main French floodplains and on the French coast for the first cycle of flood directive. Data is provided in several formats but the easier is the raster file, with grid cells of $1 \mathrm{~m}$ and an elevation root-mean-square error of $20 \mathrm{~cm}$.

The topographic analysis explained on this article aim to, on the one hand, detect floodplain structures and give preliminary understanding of the flood dynamic on large area using GIS tools while retaining the DTM resolution of $1 \mathrm{~m}$.

On the other hand, the locations found of the floodplain structures such as river banks, embankments can be the inputs of numerical hydraulic models.

\section{Automatic detection of floodplain structures}

The objective is to identify structures, natural or artificial, on digital terrain models with automated tools to extract information on large areas. In the floodplain, those structures can be dikes, roadway or railway embankments, coastal dunes...

Several algorithms for detecting geomorphological characteristics work around curvature [1]. This type of approaches has been first implemented without success. Finally, what a person can see when located at the top of a dyke has been translated mathematically.

So the algorithm developed is based on the calculation of elevation around a given point. To explain the calculation, Figure 1 depicts the principle in crosssection. For each cell in a DTM, the maximum left elevation $(\Delta \mathrm{g})$ and the maximum right elevation $(\Delta \mathrm{d})$ are calculated. The width of calculation (12 pixels in Figure 1 ) is configurable, as it will be explained latter. Then minimum of those two values are quoted on the cell. By keeping the minimum value, positive value means that the point is located closed to the ridge or in the upstream and downstream slope of the structure.

As the result, a new grid is obtained with a high cell value on top of structures, a decreasing value on slopes and a negative or very low value on adjacent low land. In order to lighten the grid, negative cell values are not saved but replaced by "no data" cells.

\footnotetext{
a Corresponding author: celine.trmal@cerema.fr
} 


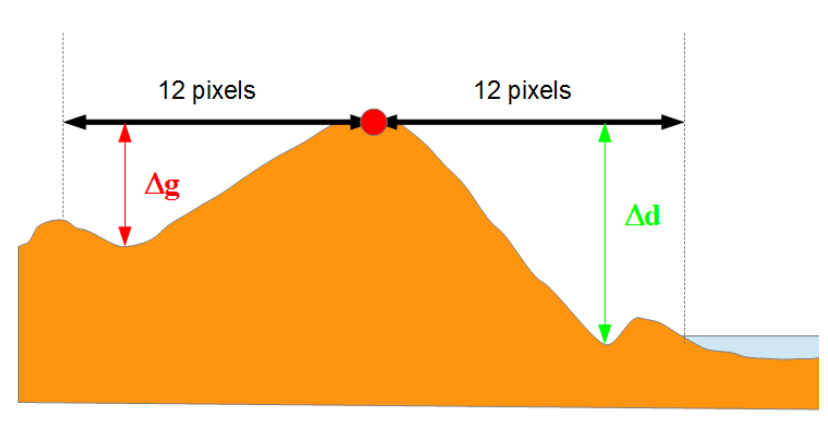

Figure 1. Sketch of the algorithm in 2D

In $3 \mathrm{D}$, the algorithm is calculated in four directions as the direction of the structures is not known in advance. The calculation is still done over a certain width on either side of the point. The maximum of the four values obtained are saved in the center cell. After calculation, if there is an embankment, the result is the height of the embankment.

The algorithm allows to identify by coloring the grid obtained the structures both in river floodplains and coastal low lands. Figure 2 illustrates a result on a river floodplain (Var river). In order to focus only on the floodplain, as the algorithm also identifies natural ridges as hill ridges, the EAIP is displayed (maximum flood prone area). The EAIP was produced during the Preliminary Flood Risk Assessment of the EU Floods Directive and so it is available throughout France.

This width of calculation was adjusted. As it can be seen on Figure 2, a higher width allows detecting larger structures. Indeed calculation has been done for 3 widths:

- $\quad 9 \mathrm{~m}$ width, any embankment is detected.

- $25 \mathrm{~m}$ width, cycle road on the right hand side of Var river appears as well as other embankments on the right hand side of the Esteron river.

- $51 \mathrm{~m}$ width, road embankments on the left hand side are detected.

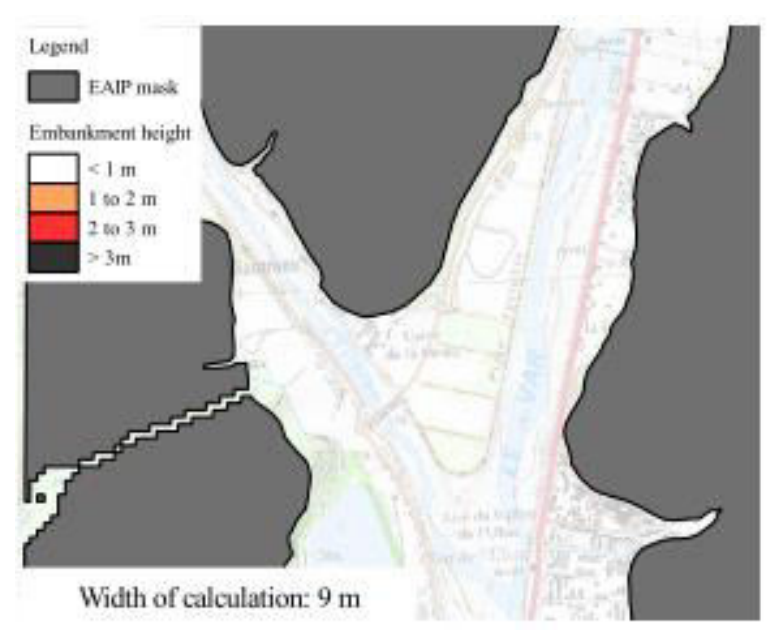

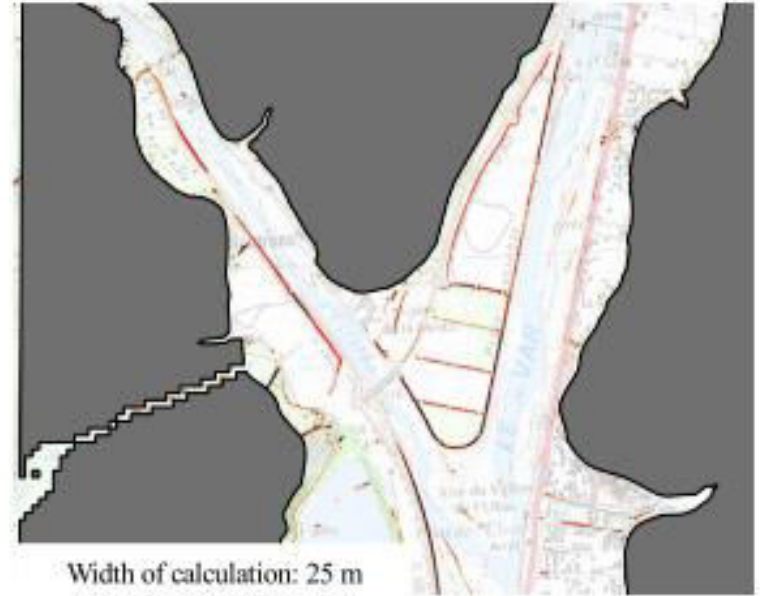

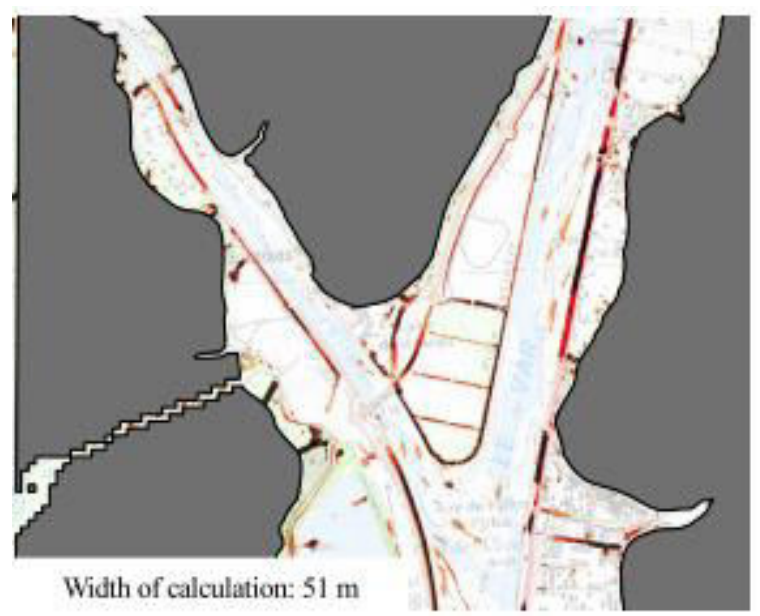

Figure 2. Examples of results for the Var river

Figure 3 illustrates a result on a coastal area, in Camargue. The sea dike is well identified as well as the coastal defense structures of Les Saintes Maries de la Mer. The width of calculation is $51 \mathrm{~m}$. Sand dunes appear also in deferent areas.

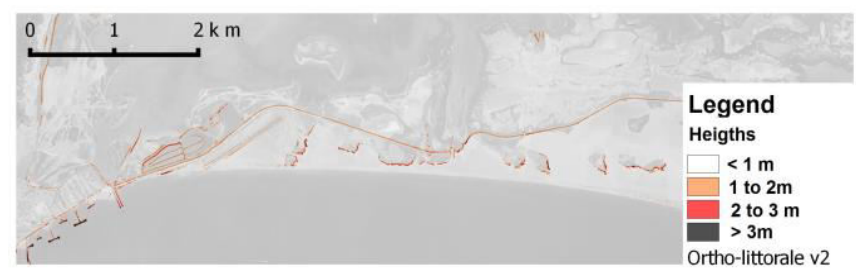

Figure 3. Camargue

Figure 4 shows also the influence of the width parameters on the identification of a sand dune system. That sand dune system is large and hilly, not straight, so more difficult to detect. In order to improve the detection, the result is colored when the cell value is higher than 0.5 $\mathrm{m}$, whereas in Figure 2 and 3 it is colored when the value is higher than $1 \mathrm{~m}$. 


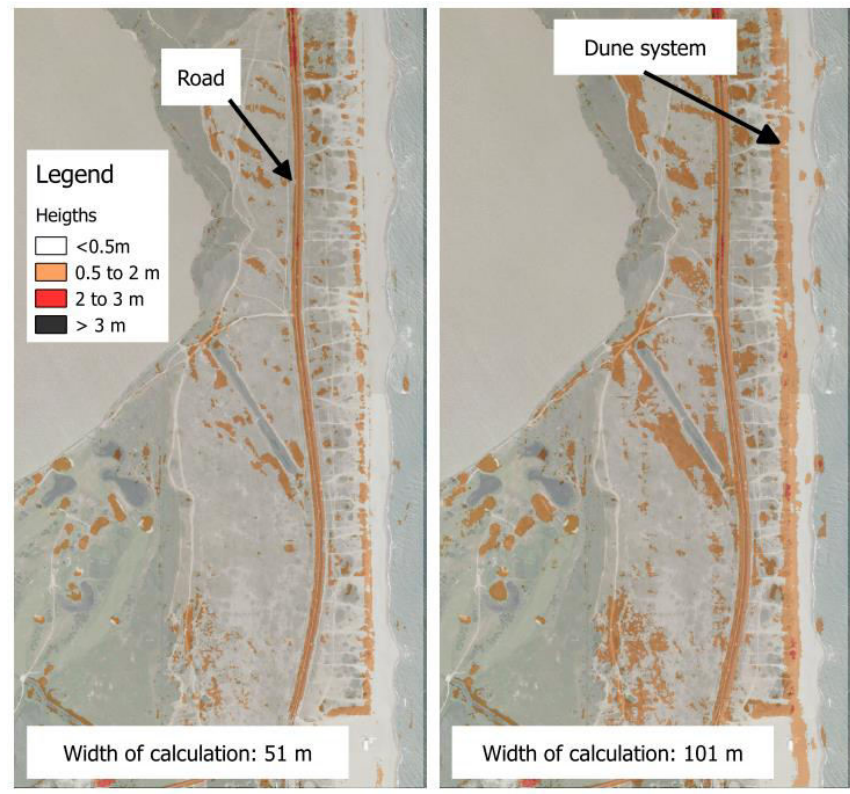

Figure 4. Sand dune system between Saint-Cyprien Plage and Canet Plage

\section{Detailed mapping of floodplain structures}

The previous method gives the position of the floodplain structures as dykes, sand dunes and also transport infrastructures. However for a certain number of uses the exact locations of the crest, toe... of those structures are necessary, especially before implementing hydraulic modeling.

\subsection{Crest lines of flood protection structures}

The first idea was to draw transects to the footprint of the previously identified structures to quote the point of maximum elevation in each transect. Especially for no linear structures such as dunes, joining all the higher points doesn't represent the crest.

On the other side, the method of least cost path exposed by Hardin et al [2] permits to extract the crest lines.

The first step is to point out two points manually at the opposite ends of the structures. They have to be closed to the structures, but the identification of the crest is not sensitive to the location of those points.

Then a cost surface is generated from the DTM. From that cost surface, a cumulative cost surface between the two points is calculated. By solving the least cost path from the second point to the first one, the crest line appears.

To implement that method, Grass GIS software has been applied as follows:

- the cost surface is computed from the formulae $\exp (-5$ DTMcell). The factor 5 has been chosen after sensitivity analysis

- the cumulative cost surface is computed by the r.cost tool between the two points

- the least cost path from the second point is computed by the r.drain tool
- the result in a grid format is first thinned with the r.thin tool

- and then vectorized by the r.to.vect tool.

That method has been tested in coastal sand dunes. The along profile of the crest dune and the method of flooding from sea (see paragraph 4) confirm that the crest line goes through the low lying passage (see Figure 5).
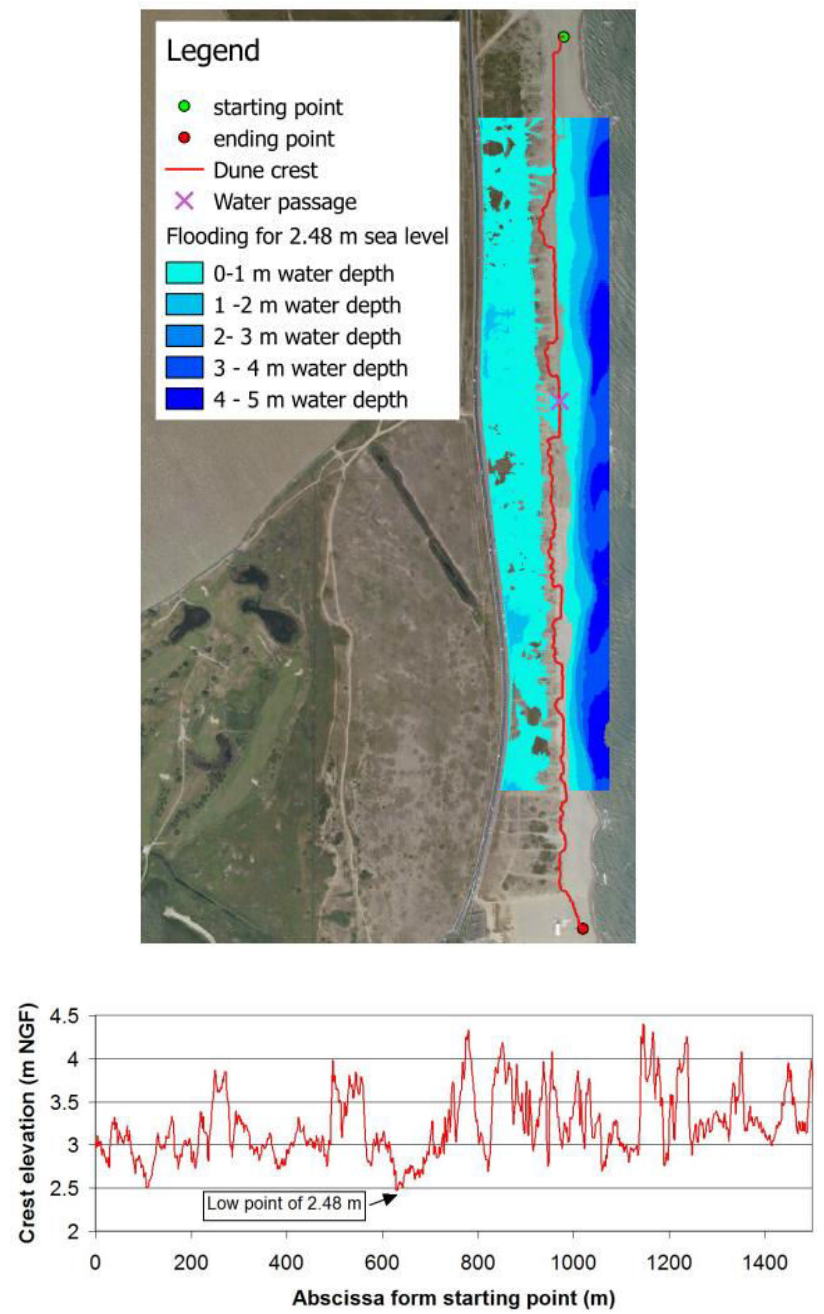

Figure 5. Crest of sand dunes and its along profile (Canet)

This method is particularly useful when dike ends have been already recorded in a database (such as Siouh in France).

\subsection{River banks}

The detection of river banks is more difficult because their slope is only visible on river side and they aren't very high above the riverbed, not really distinguishable.

Applying the least cost method directly on the DTM doesn't allow to get river banks.

To characterize river banks the curvature has been used.

The curvature of the DTM, as it presents a slope at each side of the river banks (see Figure 6, first set of profiles), is a good input for the method of least cost path 
explained above. Before implementation, some grid manipulations on GIS software are necessary.

First of all it is to compute the curvature. As the DTM presents a rough surface, better results of highlighting are obtained when the DTM is first smoothed by a gauss filter. Depending on the site, the size of the neighbored window for applying the filter needs to be adjusted. In the tests carried out, a 25 meter window is working well for river bank. The curvature is computed with the r.param.scale tool.

The grid of the DTM curvature contains very small cell values. Consequently that grid is normalized by its maximum and multiplied by 10 (see Figure 6 second set of profiles).

In order to have a calculation for the right and left river banks separately, a value of -100 is affected on the middle of the river.

Then the difficulty is to choose the starting and ending points for the least cost path analysis as any algorithms or database give the approximate location of river banks. As the least cost path analysis is not sensitive to the choice of those points, they have been located on the river bed. Two sets are drowned, one for the right side and another for the left side. They have to be closed enough especially when other rivers are flowing to the main river (see Figure 7).

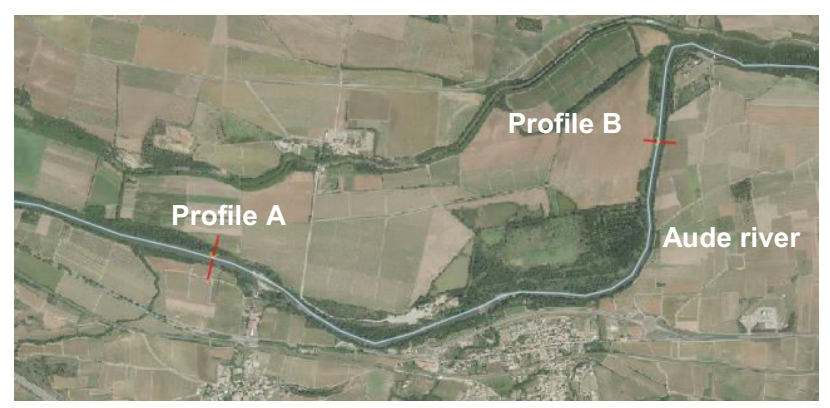

Profile A
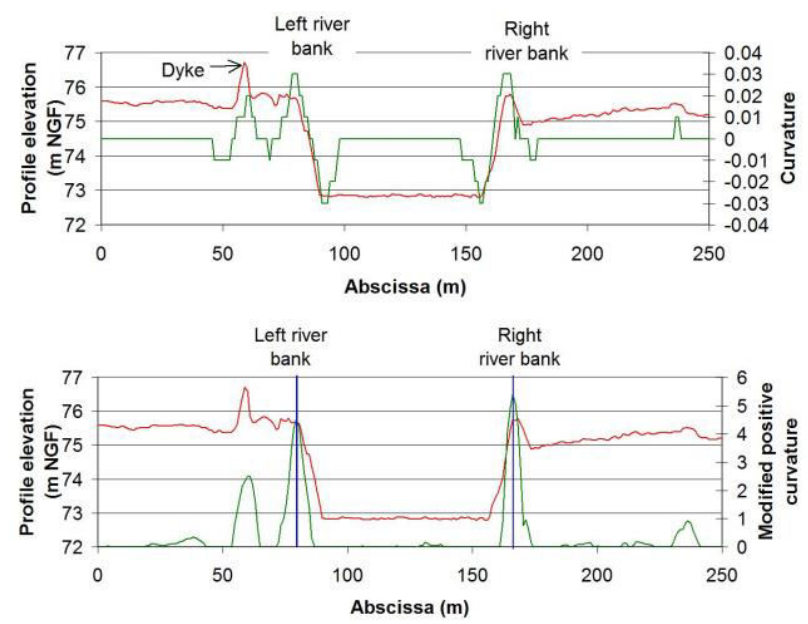

Profile B

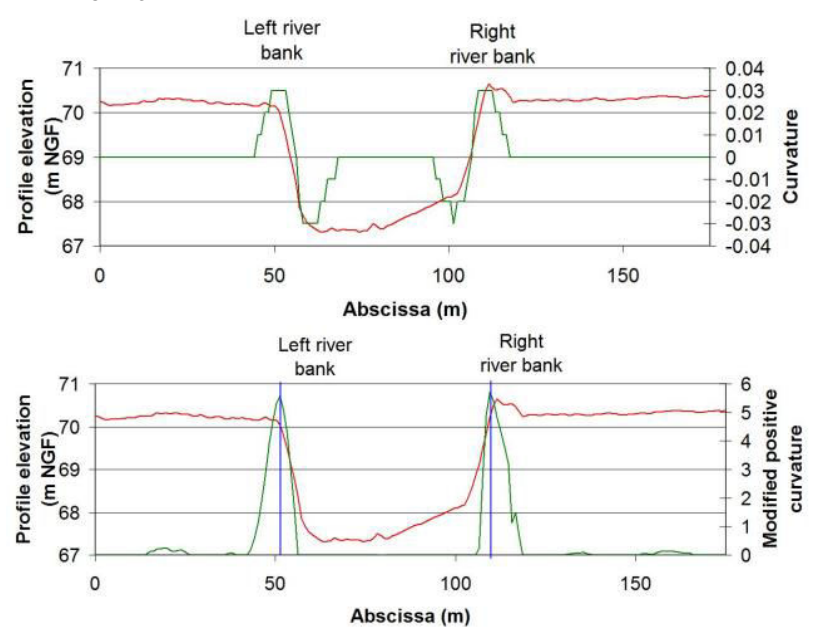

Figure 6. River bank profile (red line) with its curvature and its modified curvature (green lines)

Figure 7 shows the result for the example of the Aude river. It can be seen that river banks are sometimes interrupted by other rivers flowing in the main river.

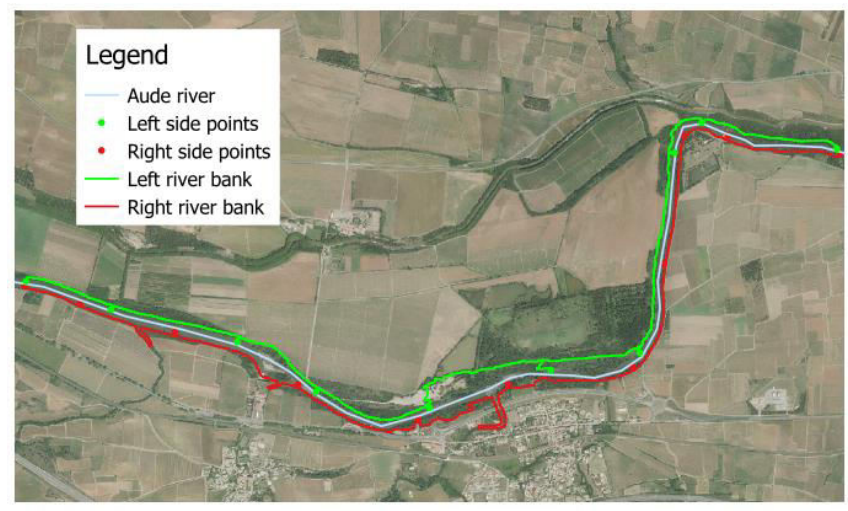

Figure 7. Aude river results

\section{Level of protection of coastal systems and outline of the protected area}

In coastal areas, as the sea floodplain is almost flat, it is possible to go further in the analysis of the floodplain structures, especially flood defense systems, still using topographic analysis.

Comparison of two methods of topographic analysis of low-lying coastal areas can improve the knowledge on the protected areas by flood defense systems.

The first topographic analysis is classic. It consists in identifying the area as flood-prone when the terrain elevation is lower than a given sea level whether or not it is far from the sea.

The second topographic analysis implemented consists to identify only low areas connected to the sea. The diffusion of water starts from a cell in the sea. The diffusion to hinterland is computed cell by cell when the elevation of adjacent cells is lower that the sea. In this case, if the algorithm encounters a barrier of cell higher 
than the sea level, it stops and does not flood lower areas unconnected to the sea. The r.lake tool of Grass software is implemented.

For a given sea level, the difference in expansion between the first and second analysis brings out low areas not connected to the sea for this level and therefore potentially protected for that level.

The analysis is conducted with different sea levels spaced at constant pitch (eg $25 \mathrm{~cm})$. At the end, in the identified areas, the maximum sea level which does not flood the area is affected to the grid cell. In other words, with a higher sea level of $25 \mathrm{~cm}$ (value of the example), the area is flooded by the GIS tool. A result map is shown on Figure 8.

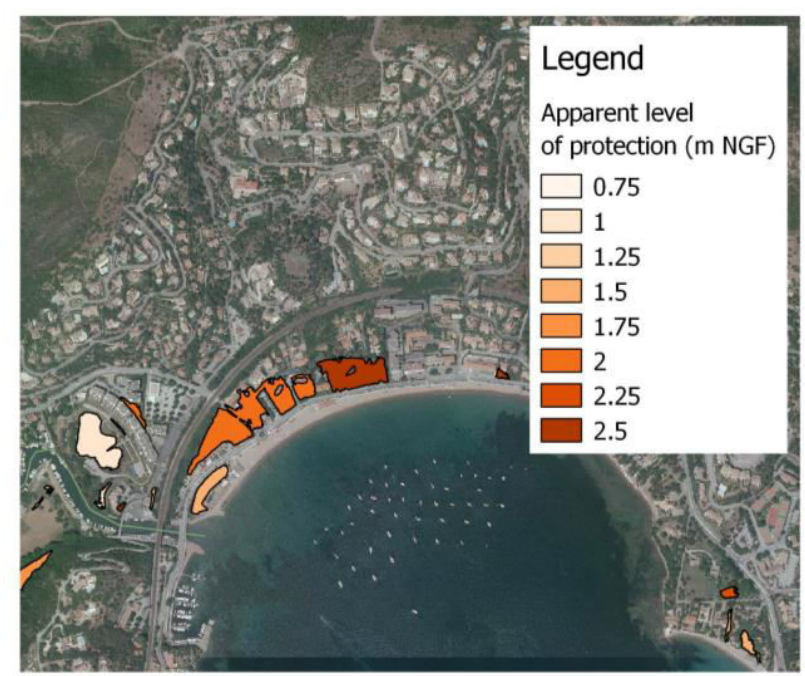

Figure 8. Example of protected areas (Agay bay)

This process allows, in the case of an area protected by a defense system, to approach the height of the system, at least to identify its lowest point.

As the elevation of all cells is analyzed step by step to spread the flood, the quality of the result depends largely on the quality of the DTM used.

The limitations of the method come also from the diffusion algorithm that floods from cell to cell with a diffusion that can be diagonal, meaning that a low point of one meter wide may make enter an infinite volume of water in the backward area. The method thus tends to assign a level of protection of the area below reality.

\section{Conclusions and prospects}

Topographic analysis presented in this article allows characterizing the floodplain structures such as natural or artificial embankments or river bed. In coastal zone the protected zone could be outlined and a protection level approximated.

Topographic analysis conducted on high resolution DTM has its place in the hazard maps production, especially for larger coastal stretches. Indeed as noted by Perini et al [3], to compute hydraulic models on large area the resolution of DTM is often lowered, which leads to a reduction of the accuracy of flood maps despite a more realistic hydraulic computation.

All the GIS manipulations were automatized to cut time of implementation in a tool named DICARTO. It can be downloaded from the web [4].

\section{References}

1. Wood J. (1996) The geomorphological characterisation of Digital Elevation Models. PhD thesis, University of Leicester, UK.

2. Hardin E., Kurum, M. O., Mitasova H. and Overton M. F. (2012). Least Cost Path Extraction of Topographic Features for Storm Impact Scale Mapping. Journal of Coastal Research, Vol. 28, Issue 4, pp. 970 - 978.

3. Perini L., Calabrese L., Salerno G., Ciavola P. and Armaroli C. (2016). Evaluation of coastal vulnerability to flooding: comparison of two different methodologies adopted by the EmiliaRomagna region (Italy). Nat. Hazards Earth Syst. Sci., 16, pp. 181-194

4. Trmal C., Pons F. and Alquier M. (2015) Notice de DICARTO packagé en R, Available at: http://wikhydro.developpementdurable.gouv.fr/index.php/ Notice_de_DICARTO_packag\%C3\%A9_avec_R 